\title{
STANDARD TENSILE TEST COMPARED TO THE SMALL PUNCH TEST OF ALUMINIUM ALLOY
}

\author{
F. Šebek ${ }^{*}$, P. Kubík ${ }^{* *}$, J. Petruška ${ }^{* * *}$
}

\begin{abstract}
The paper deals with certain similarities in results of standard tensile testing and small punch tests. The study is conducted using wrought aluminium alloy 2024-T351, which is solution heat treated, stressrelieved stretched and then cold worked. This aerospace alloy has been rarely used in small punch testing, but it is well documented by standard testing techniques. Basic mechanical properties obtained by two distinct methods are compared and main consequences of the empirical estimations from the small punch testing are concluded.
\end{abstract}

Keywords: clearance, failure, damage accumulation, finite elements, plasticity

\section{Introduction}

The Small Punch Test (SPT) is a miniaturized test providing the information about mechanical properties (Rouse et al., 2013). It can be used for applications where there is a shortage of material (Kubík et al., 2017) or in cases where there are very specific environmental conditions, as irradiation (Campitelli et al., 2005). It can also be used for investigation of local mechanical properties and study of microstructure (Dobeš et al., 2015). Furthermore, it can be used for elevated temperatures easily (Dymáček, 2016), while the creep is targeted (Dobeš and Dymáček, 2016). The small punch test is used for ductile fracture as well (Šebek et al., 2017).
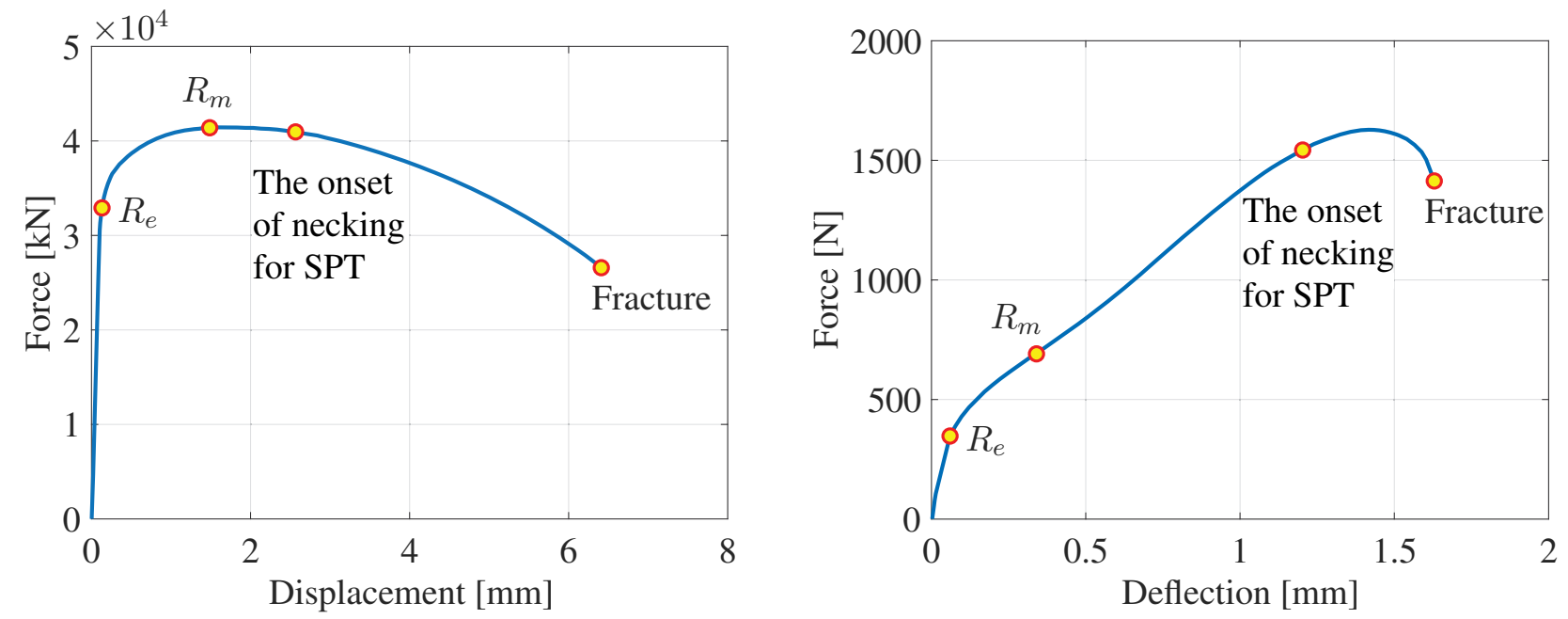

Fig. 1: The example of link between tensile (left) and small punch test (right), as proposed by Hůlka (2014).

\footnotetext{
Ing. František Šebek, Ph.D.: Institute of Solid Mechanics, Mechatronics and Biomechanics, Faculty of Mechanical Engineering, Brno University of Technology, Technická 2896/2; 616 69, Brno; CZ, sebek@ fme.vutbr.cz

** Ing. Petr Kubík, Ph.D.: Institute of Solid Mechanics, Mechatronics and Biomechanics, Faculty of Mechanical Engineering, Brno University of Technology, Technická 2896/2; 616 69, Brno; CZ, kubik.p@ fme.vutbr.cz

**** Prof. Ing. Jindřich Petruška, CSc.: Institute of Solid Mechanics, Mechatronics and Biomechanics, Faculty of Mechanical Engineering, Brno University of Technology, Technická 2896/2; 616 69, Brno; CZ, petruska@ fme.vutbr.cz
} 
While simple material models are still in use with practical applications (Petruška et al., 2012), where the lack of data is typical for industry (Petruška et al., 2016), there is a demand on complex material description in academia (Šebek et al., 2014). The penetration technique is a prospective adept for that (Krčmár and Materna, 2014).

It has been suggested that here is a link between the standard tensile experiments and small punch tests in some characteristic points, as proposed by Hůlka (2014). These characteristic points are usually the yield stress (yield strength) $R_{e}$ and ultimate tensile strength $R_{m}$. Furthermore, it can be the onset of necking for small punch tests and finally, the fracture itself. All the important points are depicted in Fig. 1. All the characteristics determined in small punch testing are measured in lower order values than in tensile tests, which implies high demands on precision of the measuring system. Apart from the friction, there is non-negligible influence of the clamping conditions (Andrés and Dymáček, 2016).

\section{Experiments}

There were conducted 5 tensile tests of standard specimens with $6 \mathrm{~mm}$ diameter and $30 \mathrm{~mm}$ gauge length. The testing was performed using Zwick Z250 Allround-Line, tCII, and extensometer Zwick multiXtens. Force-displacement curves with the averaged one are in Fig. 2 (left) with minimum scatter. The test speed was $1 \mathrm{~mm} / \mathrm{min}$ until the yield point and then it was smoothly shifted to $2 \mathrm{~mm} / \mathrm{min}$.
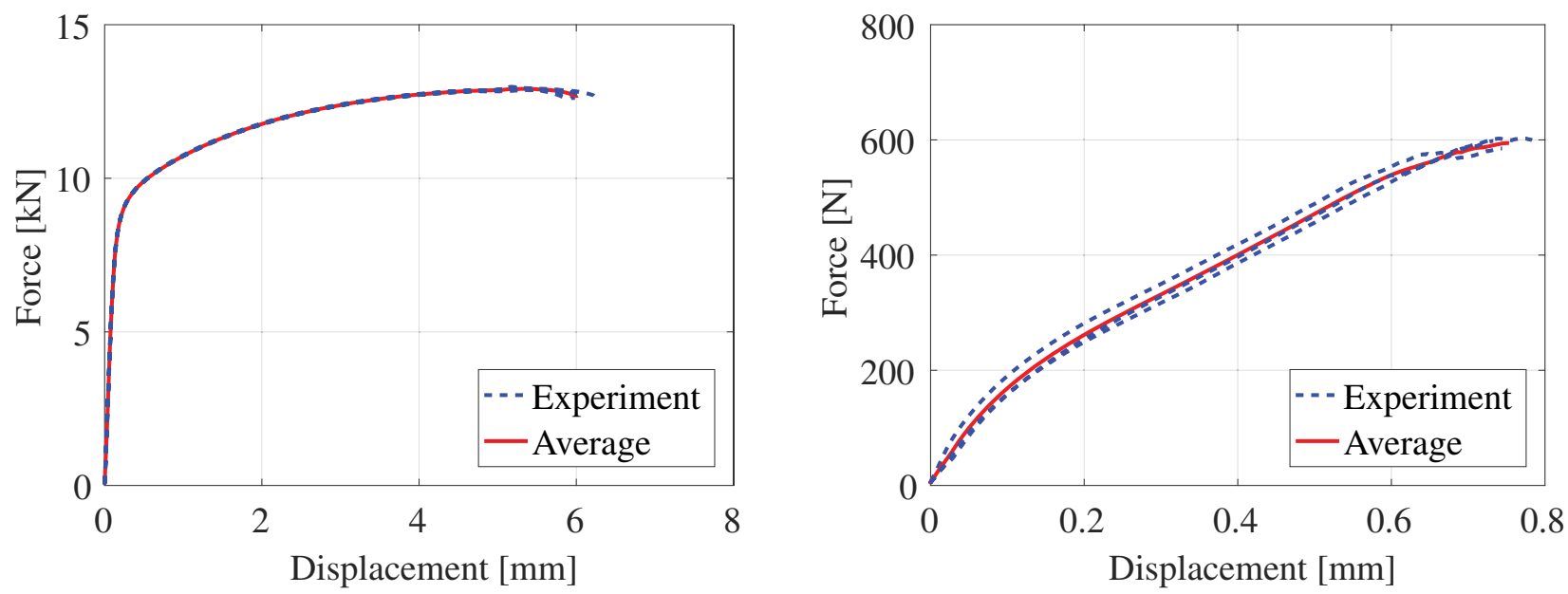

Fig. 2: Force-displacement curves from standard tensile tests (left) and small punch tests (right).

There were carried out 3 small punch tests of discs with $8 \mathrm{~mm}$ diameter and initial thickness $h_{0}=0.5 \mathrm{~mm}$ on the same testing machine as standard tensile experiments. Results are depicted with the averaged forcedisplacement curve in Fig. 2 (right). The test speed was constantly 1 mm/min.

The loading was quasi-static at room temperature for all tests.

\section{Calculations}

The yield stress can be calculated as follows

$$
R_{e}=\beta \frac{F_{e}}{h_{0}^{2}}
$$

where $\beta$ is the dimensionless material constant and $F_{e}$ is the elastic-plastic transition load. Mao and Takahashi (1987) proposed that $\beta=0.360$. The $F_{e}$ can be estimated by the secant method.

The ultimate tensile strength can be estimated as

$$
R_{m}=\beta_{1} \frac{F_{m}}{h_{0}^{2}}+\beta_{2}
$$

where $\beta_{1}$ and $\beta_{2}$ are two material constants and $F_{m}$ is the maximum load. Mao and Takahashi (1987) suggested that $\beta_{1}=0.130$, which is dimensionless, and $\beta_{2}=320 \mathrm{MPa}$. 
The code of practise (CEN, 2007) defines a bilinear function that goes from the origin through two points, $\mathrm{A}$ and $\mathrm{B}$, as

$$
f(u)= \begin{cases}\frac{f_{\mathrm{A}}}{u_{\mathrm{A}}} u & \text { for } 0 \leq u<u_{\mathrm{A}} \\ \frac{f_{\mathrm{B}}-f_{\mathrm{A}}}{u_{\mathrm{B}}-u_{\mathrm{A}}}\left(u-u_{\mathrm{A}}\right)+f_{\mathrm{A}} & \text { for } u_{\mathrm{A}} \leq u \leq u_{\mathrm{B}}\end{cases}
$$

where $f_{\mathrm{A}}$ is the load at point $\mathrm{A}, u$ is the displacement, $u_{\mathrm{A}}$ is the displacement at point $\mathrm{A}, f_{\mathrm{B}}$ is the load at point $\mathrm{B}$ and $u_{\mathrm{B}}$ is the displacement at point $\mathrm{B}$. When $u_{\mathrm{B}}=h_{0}$, then $u_{\mathrm{A}}, f_{\mathrm{A}}$ and $f_{\mathrm{B}}$ can be varied so the following error is minimized

$$
e=\int_{0}^{u_{\mathrm{B}}}[F(u)-f(u)]^{2} \mathrm{~d} u
$$

where $F(u)$ is the load punch displacement curve.

The testing machine with its extensometer was in accuracy class 0.5 according to EN ISO 9513. This corresponds to the relative error of the nominal full scale reading in percentage. Then, $0.5 \%$ should be precise enough.

The fitting was done within MATLAB R2016b using non-linear least square method with the result of $u_{\mathrm{A}}=0.095 \mathrm{~mm}, f_{\mathrm{A}}=176 \mathrm{~N}$ and $f_{\mathrm{B}}=477 \mathrm{~N}$ for $u_{\mathrm{B}}=0.499 \mathrm{~mm}$, which is approximately equal to the initial thickness. The fit is depicted in Fig. 3. Then, $F_{e}=F\left(u_{\mathrm{A}}\right)=163 \mathrm{~N}$, which corresponds to the yield stress $R_{e}=235 \mathrm{MPa}$ according to one of the above equations.

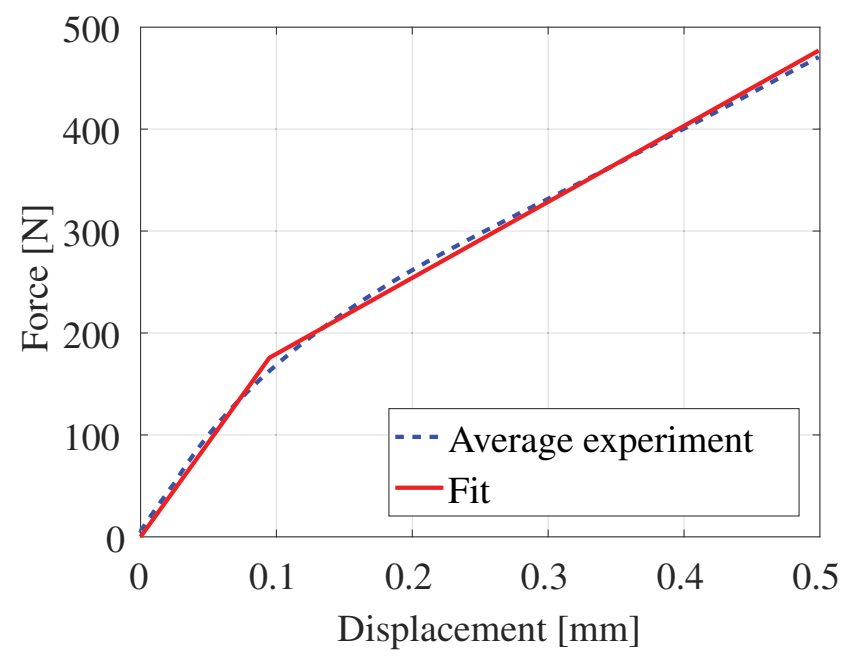

Fig. 3: The load punch displacement curve with least square fit.

The maximum load from small punch testing was $F_{m}=595 \mathrm{~N}$. Accordingly, the estimated ultimate tensile strength is $R_{m}=629 \mathrm{MPa}$ with respect to the above equation. It should be noted that the aluminium alloy 2024-T351 is quite brittle, so maximum load corresponds to the fracture in the same moment.

Both results from small punch tests are compared to the standard tensile testing in Tab. 1. It should also be noted that the yield stress is the proof stress in the case of tensile test in Tab. 1, because this aluminium alloy does not exhibit a yield point.

Tab. 1: Comparison of results from tensile and small punch testing.

\begin{tabular}{ccc}
\hline & Yield stress [MPa] & Ultimate tensile strength [MPa] \\
\hline Standard tensile test & 300 & 741 \\
Small punch test & 235 & 629 \\
\hline Difference [\%] & -22 & -15 \\
\hline
\end{tabular}




\section{Conclusions}

There is a big boom in miniaturized testing in recent years, as small punch test, shear punch test or disc bend test, despite it has not been standardized yet. There are several reasons for using that technique, which mainly include investigating the local properties of microstructures, such as the weldments, heat affected zones or transition layers. Small punch test can be used for determining the R-curves in fracture mechanics (Kumar et al., 2016). It can also perspectively contribute to the more accurate life assessment and extend the service life of components in industry.

Several experiments were done with aluminium alloy 2024-T351 to see the correlation between standard tensile test and SPT. It can be seen that used approximations underestimate the results obtained by standard tensile tests. Difference can be probably contributed to the different geometry of SPT. Then, the ultimate tensile strength is reached way before the maximum load on the circumference of the bottom surface, but not through the thickness, where the stresses are not homogeneously distributed. The onset of necking occurs when the stress reaches ultimate tensile strength through the thickness, as it can be computationally investigated. This point can still be before the maximum load, because this can happen only in location on the circumference where the weakest material point is. Then, the global force response can still increase slightly until the stress, which equals or exceeds the ultimate tensile strength, is developed through the thickness along the whole circumference.

\section{Acknowledgments}

This work is an output of project NETME CENTRE PLUS (LO1202) created with financial support from the Ministry of Education, Youth and Sports under the "National Sustainability Programme I".

\section{References}

Andrés, D. and Dymáček, P. (2016), Study of the upper die clamping conditions in the small punch test. Theoretical and Applied Fracture Mechanics, Vol. 86, Part A, pp. 117-123.

Campitelli, E. N., Spätig, P., Bertsch, J. and Hellwig, C. (2005), Assessment of irradiation-hardening on Eurofer97' and Zircaloy 2 with punch tests and finite-element modelling. Materials Science and Engineering A, Vols. 400-401, pp. 386-392.

CEN (2007), Small punch test method for metallic materials, CWA 15627.

Dobeš, F. and Dymáček, P. (2016), Fracture-based correlation of uniaxial and small punch creep data. Theoretical and Applied Fracture Mechanics, Vol. 86, Part A, pp. 34-38.

Dobeš, F., Dymáček, P. and Besterci M. (2015), Estimation of the mechanical properties of aluminium and an aluminium composite after equal channel angular pressing by means of the small punch test. Materials Science and Engineering A, Vol. 626, pp. 313-321.

Dymáček, P. (2016), Recent developments in small punch testing: Applications at elevated temperatures. Theoretical and Applied Fracture Mechanics, Vol. 86, Part A, pp. 25-33.

Hůlka, J. (2014),Computational prediction of ductile fracture, Doctoral Thesis, Faculty of Mechanical Engineering, Brno University of Technology, Brno (in Czech).

Krčmář, M. and Materna, A. (2014), Assessment of the constitutive properties of reactor steel using an inverse analysis on the small punch test. In: Engineering Mechanics 2014, IT ASCR, Prague, pp. 332-335.

Kubík, P., Petruška, J., Hůlka, J. and Šebek, F. (2017), Simulation of the small punch test of AISI 316L austenitic steel. In: Engineering Mechanics 2017, IT ASCR, Prague, pp. 542-545.

Kumar, P., Dutta, B. K., Chattopadhyay, J. and Shriwastaw, R. S. (2016), Numerical evaluation of J-R curve using small punch test data. Theoretical and Applied Fracture Mechanics, Vol. 86, Part B, pp. 292-300.

Mao, X. and Takahashi, H. (1987), Development of a further-miniaturized specimen of $3 \mathrm{~mm}$ diameter for tem disk $(\varnothing 3 \mathrm{~mm})$ small punch tests. Journal of Nuclear Materials, Vol. 150, Issue 1, pp. 42-52.

Petruška, J., Návrat, T. and Šebek, F. (2012), A new model for fast analysis of leveling process. Advanced Materials Research, Vol. 586, pp. 389-393.

Petruška, J., Návrat, T., Benešovský, M. and Šebek, F. (2016), Optimal intermeshing of multi roller cross roll straightening machine. In: AIP Conference Proceedings, Vol. 1769, pp. 120002-1-120002-4.

Rouse, J. P., Cortellino, F., Sun, W., Hyde, T. H. and Shingledecker, J. (2013), Small punch creep testing: Review on modelling and data interpretation. Materials Science and Technology, Vol. 29, Issue 11, pp. 1328-1345.

Šebek, F., Kubík, P. and Petruška, J. (2014), Localization problem of coupled ductile failure models compared to uncoupled ones. In: Engineering Mechanics 2014, IT ASCR, Prague, pp. 632-635.

Šebek, F., Petruška, J. and Kubík, P. (2017), Ductile fracture criteria implementation and calibration using the tensiontorsion tests. In: Engineering Mechanics 2017, IT ASCR, Prague, pp. 854-857. 